\title{
Prevalence and Correlation between TMD Based on RDC/TMD Diagnoses, Oral Parafunctions and Psychoemotional Stress in Polish University Students
}

\author{
Mieszko Wieckiewicz, ${ }^{1}$ Natalia Grychowska, ${ }^{2}$ Kamil Wojciechowski, ${ }^{2}$ Anna Pelc, ${ }^{2}$ \\ Michal Augustyniak, ${ }^{2}$ Aleksandra Sleboda, ${ }^{2}$ and Marek Zietek ${ }^{3}$ \\ ${ }^{1}$ Division of Dental Materials, Faculty of Dentistry, Wroclaw Medical University, 26 Krakowska Street, 50425 Wroclaw, Poland \\ ${ }^{2}$ Faculty of Dentistry, Wroclaw Medical University, 26 Krakowska Street, 50425 Wroclaw, Poland \\ ${ }^{3}$ Department of Periodontology, Faculty of Dentistry, Wroclaw Medical University, 26 Krakowska Street, 50425 Wroclaw, Poland \\ Correspondence should be addressed to Mieszko Wieckiewicz; m.wieckiewicz@onet.pl
}

Received 2 June 2014; Accepted 22 June 2014; Published 9 July 2014

Academic Editor: Anna Paradowska-Stolarz

Copyright (C) 2014 Mieszko Wieckiewicz et al. This is an open access article distributed under the Creative Commons Attribution License, which permits unrestricted use, distribution, and reproduction in any medium, provided the original work is properly cited.

\begin{abstract}
The aim of the study was to assess the prevalence of temporomandibular disorders (TMD) and oral parafunctions, as well as their correlation with psychoemotional factors in Polish university students. The research was conducted in a group of 456 students $(N=456)$. The examination form comprised of two parts: survey and clinical examination. The research diagnostic criteria for temporomandibular disorders (RDC/TMD) was used in order to assess TMD. Symptoms of TMD were observed in 246 (54\%) students after clinical examination. The largest group involved students with disc displacement (women: 132, 29\%; men: $70,15 \%)$. Women $(164 ; 36 \%)$ suffered more frequently than men $(82 ; 18 \%)$ from problems related to the stomatognathic system $(P<0.05)$, described themselves as easily excitable and emotionally burdened, and reported symptoms as tightness of the facial and neck muscles $(P<0.05)$. In $289(64 \%)$ students intraoral symptoms concerning occlusal parafunctions were observed. In 404 (89\%) examined students, nonocclusal parafunctions were recorded. A significant correlation between TMD and psychoemotional problems could be detected. TMD symptoms more often concern women. Emotional burden and excitability are factors predisposing muscular disorders.
\end{abstract}

\section{Introduction}

The temporomandibular disorders (TMD) and oral parafunctions seem to be a frequent problem in modern societies [1-6]. The etiopathology of the temporomandibular joints is related to muscles, teeth arches, and periodontium. Their main causes involve both pathophysiological and psychosocial factors $[7,8]$. In the literature, a significant impact of the psychoemotional factor is reported, comparable to the impact of other factors concerning physical health such as systemic diseases, malocclusions, loss of teeth, traumas, and microtraumas [9-12]. Stress, fatigue, anxiety, depression, sleep disorders, and a fast pace of life affect negatively the human psyche [13]. In those patients muscular related TMD is observed more often [14]. Moreover different studies report that TMD coexists with other numerous disorders such as SAPHO syndrome (synovitis, acne, pustulosis, hyperostosis, and osteitis syndrome), fibromyalgia, back- or spine ache, chronic fatigue syndrome, spastic colons, sleep disorders, congenital defects, headaches, and arthritis [11, 12, 15, 16]. Many studies report that the symptoms of the masticatory system disorders are more frequent in women than in men [2-5]. This may result from biological differences, including hormonal ones, and also psychosocial factors [17, 18]. Stallman reports that student population lives more under stress than the general population and develops considerably often TMD and oral parafunctions [19]. The possible stress factors include poor learning achievements, financial problems, unergonomic body position while studying, exams, submitting academic papers, and the necessity to become 
independent [19-21]. Another predisposing factor to the occurrence of the masticatory system disorders in students is the age of this population, since the peak of the development of the symptoms is between 20 and 40 years of age [3].

The aim of this epidemiological study is to assess the prevalence of temporomandibular disorders and oral parafunctions among Polish university students and their correlation with psychoemotional factors.

\section{Materials and Methods}

The study was conducted at the four different Polish universities (Wroclaw Medical University, Wroclaw University of Technology, Wroclaw University of Environmental and Life Sciences, and University of Wroclaw) on a group of 456 students in the years 2012-2014 ( $=456)$. Inclusion criteria were that the participants should be aged between 19 and 30 years, be Polish university student (both gender were acceptable), and express consent to participate voluntarily in the study. Two hundred sixty four (58\%) women and 192 (42\%) men were examined. The mean age of participants was $22.01 \pm 2.11$ years.

The analysis was conducted by the research diagnostic criteria for temporomandibular disorders (RDC/TMD) introduced by Dworkin and LeResche in 1992 [1]. This enables the standardization of the procedures of epidemiological studies, the unification of TMD diagnostic and exploratory criteria, and the comparison of results of other similar studies. The results of the study were based on the RDC/TMD Axis I diagnostic criteria. Mental state of subjects was not assessed according to RDC/TMD Axis II diagnoses.

Before the commencement all researchers have been trained and calibrated in accordance with the adopted norms presented on the official website of the International RDC/TMD Consortium [22]. A simplified version of the examination form was used, which comprised of the survey and the clinical examination, developed on the basis of the RDC/TMD clinical physical examination form and questionnaire [23].

As first part the survey included questions concerning basic demographic data such as gender and age, type of reaction to stress, emotional burden, and occurrence of subjective symptoms of TMD such as fatigue and tightness of the facial muscles, cervical muscle pain, chronic headache, and otologic symptoms. It also included questions concerning the occurrence of nonocclusal parafunctions (habitual gum chewing, lip biting, nail biting and/or skin biting around nails, objects biting, and cheek biting).

During the second part of the clinical examination, patients were given one or more diagnoses according to RDC/TMD Axis I: group I/muscle disorders, group II/disc displacements, and group III/other common joint disorders. The study did not take into account individual unilateral diagnosis of TMD. Over the clinical examination no reliable diagnosis was possible in order to unambiguously group a patient to subgroups IIc, IIIb, or IIIc. Thus, the authors used only groups IIa, IIb, and IIIa. Intraoral symptoms of occlusal parafunctions as teeth attrition, buccal linea alba, gingival recession, crenated tongue, and cracked enamel were systematically documented in an assessment form specially made for the study.

Based on self-report, clinical criteria, and diagnosis, the patients were divided in the following groups.

Group I: Muscle Disorders

Ia Myofascial Pain

Consider the following:

(i) pain or ache in the jaw, temples, face, preauricular area, or inside the ear at rest or during function;

(ii) pain in response to palpation of three or more of the following muscle sides (right and left side count as separate sides for each muscle): posterior temporalis, middle temporalis, anterior temporalis, origin of masseter, insertion of masseter, posterior mandibular region, submandibular region, lateral pterygoid area, and tendon of the temporalis;

(iii) at least one of painful muscle must be homolateral to the reported pain.

Ib Myofascial Pain with Limited Opening

Consider the following:

(i) myofascial pain as defined in Ia;

(ii) pain-free unassisted mandibular opening $<40 \mathrm{~mm}$ interincisal distance;

(iii) maximum assisted opening (passive stretch) of $\geq 50 \mathrm{~mm}$ /greater than pain-free unassisted opening.

Group II: Disc Displacements

IIa Disc Displacement with Reduction

Consider the following:

(i) clicking in temporomandibular joint (TMJ) (click on both vertical opening and closing/occuring at a point at least $5 \mathrm{~mm}$ greater interincisal distance on opening than closing/eliminated on protrusive opening), reproducible on 2 of 3 consecutive trials;

(ii) clicking in TMJ on both vertical range of motion (either opening or closing), reproducible on 2 of 3 consecutive trials and clicking during lateral excursion or protrusion, reproducible on 2 of 3 consecutive trials.

IIb Disc Displacement without Reduction with Limited Opening

Consider the following:

(i) history of locking or catching that interfered with eating;

(ii) unassisted opening (even painful) $\leq 35 \mathrm{~mm}$ interincisal distance;

(iii) contralateral excursion $<7 \mathrm{~mm}$ and/or uncorrected deviation to ipsilateral side on opening;

(iv) absence of joint sound or presence of joint sounds not meeting criteria for disc displacement with reduction. 


\section{Group III: Other Common Joint Disorders \\ III A Arthralgia \\ Consider the following:}

(i) painful joint uni- or bilateral (lateral pole and/or posterior attachment) during palpation;

(ii) one or more painful regions (self-report): pain in the joint, pain in the joint during maximum unassisted opening, pain in the joint during assisted opening, and pain in the joint during lateral excursion;

(iii) coarse crepitus must be absent for simple arthralgia diagnosis.

The intergroup differences were tested using the chisquare test for independence and the test of difference between two proportions as appropriate. Statistical significance level was set at $P<0.05$. Statistica 10.0 was used in the conducted analysis (StatSoft Inc., Tulsa, Oklahoma, USA).

\section{Results}

3.1. Results of the First Part-Survey. From 456 examined students 194 (43\%) described themselves as easily excitable, 263 (58\%) suffered from emotional burden, 139 (30\%) reported fatigue and/or tightness of the facial muscles, 214 (47\%) cervical muscle pain and 180 (40\%) students regular headaches. Significantly more women than men reported the above symptoms $(P<0.05)$. Otologic symptoms are declared by 87 students (19\%) (Table 1). Nonocclusal parafunctions were reported from 404 (89\%) examined students. In the majority of cases no significant differences in the prevalence of nonocclusal parafunctions between genders could be detected, excluding lip biting, which is more frequent in women (Table 2).

Students who perceive themselves as easily excitable and/or as having chronic emotional burdens also reported more often fatigue and tightness of facial muscles, cervical muscle pain and headaches compared to other participants $(P<0.05)$. The prevalence of those symptoms were, respectively, $77(17 \%), 111(24 \%)$, and 88 (19\%) in the group of students defining themselves as excitable, while in the group suffering from chronic emotional burdens 111 (24\%), $154(34 \%)$, and $126(28 \%)$.

3.2. Results of the Second Part-Clinical Examination. In the second part of clinical examination TMD symptoms were found in 246 (54\%) students. More often were detected students with symptoms of disc displacements. Almost one third $(147 ; 32 \%)$ of subjects were classified in more than one diagnostic group; no one represented all TMD symptoms (Table 3$)$. Significantly more women $(164 ; 36 \%)$ than men $(82 ; 18 \%)$ suffered from stomatognathic system problems $(P<0.05)$. The prevalence of TMD symptoms and their correlation to the gender are presented in Table 4.

In group I/muscular disorders a significant higher percentage belonged to students with emotional burden and/or excitability, suffering from fatigue and tightness of facial muscles, cervical pain, and headaches (for all $P<0.05$; Table 5).
In $289(64 \%)$ students intraoral symptoms concerning occlusal parafunctions were observed (women: 166, 37\%; men: $123,27 \%)$. In most cases no differences between men and women were found, with the exception of a higher prevalence of crenated tongue in women $(P<0.05)$. No correlation was recorded between the frequency of the symptoms of occlusal parafunctions and excitability, chronic emotional burdens, fatigue, tightness of facial muscles, cervical muscle pain, and headaches, although a significant correlation between crenated tongue and students with regular headaches was observed $(P<0.05)$.

\section{Discussion}

Temporomandibular disorders have a multifactorial etiopathogenesis. Several authors underline the influence of local factors on their development, while others underline that of systemic factors $[24,25]$. The importance of psychological factors, such as increased psychoemotional activity and stress, is also emphasized in literature describing the etiology of TMD and oral parafunctions [26, 27]. In the presented study we also observed a significant role of psychoemotional factors in the TMD development. Easily excitable and emotionally burdened persons suffered significantly more often from TMD and oral parafunctions. It must be mentioned that the RDC/TMD Axis I protocol includes valid diagnostic criteria for differentiating the patients in this study into two groups, with and without TMD. Although this protocol served the scope of the study, generally enables the diagnosis of a limited number and common TMD.

Stress is also an important factor contributing to the TMD development. The examined student population is particularly susceptible to the influence of this factor [28]. Stressors may include a large number of duties, the pressure of getting a good education, an uncertain future, low income, living far away from home, and functioning in an alien environment. Moreover, students also face social, emotional, physical, and family problems [27]. Over half of the students in this study (58\%) identified themselves as emotionally burdened. According current literature this percentage could reach $72 \%$ [29] or even $90 \%$ [30] in student population. It has been proved that being under stress increases the activity of the masticatory muscles, which consequently results in TMD [31].

Further, some studies underline also the gender influence on TMD development $[32,33]$. An intercontinental research in 17 countries on 85052 adults supports that $62 \%$ of women and $38 \%$ of men suffer from TMD [34]. In similar studies in student populations the respective percentage is $65 \%$ for women and $35 \%$ for men $[32,34]$. In the presented study, a greater disproportion between the different genders $(70 \%$ women; $30 \%$ men) was detected, showing that women are more susceptible to TMD than men. This may result from the hormone level fluctuation, biological differences, social position, or higher sensitivity to pain in women [35]. The peak of the development of the symptoms is between 20 and 40 , in a reproductive period $[17,36]$. It may be caused 


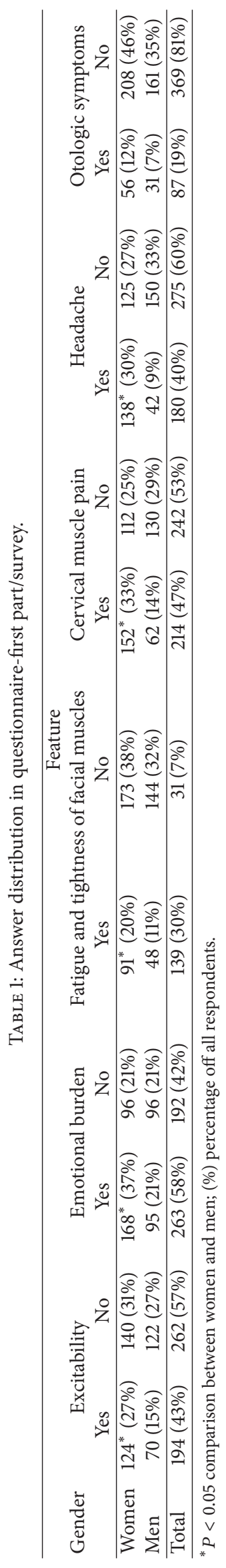


TABLE 2: Prevalence of nonocclusal parafunctions in tested population.

\begin{tabular}{|c|c|c|c|c|c|c|c|}
\hline \multirow{2}{*}{ Gender } & \multicolumn{7}{|c|}{ Feature } \\
\hline & Total & Gum chewing & Lip biting & Nail biting & Skin biting around nails & Objects biting & Cheek biting \\
\hline Women & $238(52 \%)$ & $199(44 \%)$ & $148(32 \%)^{*}$ & $49(11 \%)$ & $105(23 \%)$ & $95(21 \%)$ & $111(24 \%)$ \\
\hline Men & $166(36 \%)$ & $133(30 \%)$ & $87(19 \%)$ & $39(9 \%)$ & $63(14 \%)$ & $58(13 \%)$ & $71(16 \%)$ \\
\hline Total & $404(89 \%)$ & $332(73 \%)$ & $235(52 \%)$ & $88(19 \%)$ & $168(37 \%)$ & $153(34 \%)$ & $182(40 \%)$ \\
\hline
\end{tabular}

${ }^{*} P<0.05$ comparison between women and men; (\%) percentage off all respondents; respondents declared more than one parafunction.

TABLE 3: Distribution of single and combined RDC/TMD diagnoses in the tested population compared to the results of other studies.

\begin{tabular}{|c|c|c|c|c|c|c|c|c|c|}
\hline \multirow[b]{2}{*}{ Author } & \multicolumn{9}{|c|}{ Feature } \\
\hline & Mean age \pm SD & $\begin{array}{c}\text { Total } \\
n\end{array}$ & $\begin{array}{c}\mathrm{I} \\
n(\%)\end{array}$ & $\begin{array}{c}\text { II } \\
n(\%)\end{array}$ & $\begin{array}{c}\text { III } \\
n(\%)\end{array}$ & $\begin{array}{l}\mathrm{I}+\mathrm{II} \\
n(\%)\end{array}$ & $\begin{array}{c}\mathrm{I}+\mathrm{III} \\
n(\%)\end{array}$ & $\begin{array}{c}\mathrm{II}+\mathrm{III} \\
n(\%) \\
\end{array}$ & $\begin{array}{c}\mathrm{I}+\mathrm{II}+\mathrm{III} \\
n(\%) \\
\end{array}$ \\
\hline Achieved results & $22,01 \pm 2,11$ & 456 & $82(18,0)$ & $202(44,3)$ & $81(17,8)$ & $53(11,6)$ & $42(9,2)$ & $52(11,4)$ & 0 \\
\hline Karibe et al. [38] & $17 \pm 0,9$ & 167 & $59(48,8)$ & $56(46,3)$ & $6(4,9)$ & - & - & - & - \\
\hline Miyake et al. [39] & $20,4 \pm 2,1$ & 3557 & - & $1483(41,7)$ & $569(16)$ & - & - & - & - \\
\hline Poveda-Roda et al. [40] & $40,5 \pm 18,7$ & 850 & $299(35,2)$ & $436(51,3)$ & $115(13,4)$ & - & - & - & - \\
\hline Manfredini et al. [41] & $32,7 \pm 14,5$ & 243 & $9(4,5)$ & $24(12,1)$ & $38(19,1)$ & $4(2)$ & $38(19,1)$ & $43(21,6)$ & $43(21,6)$ \\
\hline Guarda-Nardini et al. [42] & $41,7 \pm 17$ & 383 & $16(12,6)$ & $27(21,3)$ & $78(61,4)$ & - & - & - & - \\
\hline
\end{tabular}

$n$ number of examined; (\%) percentage of examined; “-” not included in the study.

TABLE 4: Prevalence of TMD symtpoms according to the gender.

\begin{tabular}{|c|c|c|c|c|c|c|c|}
\hline \multirow{4}{*}{ Gender } & \multicolumn{7}{|c|}{ Feature } \\
\hline & \multirow{2}{*}{\multicolumn{3}{|c|}{$\begin{array}{c}\text { GROUP I } \\
\text { Muscle disorders }\end{array}$}} & \multirow{2}{*}{\multicolumn{3}{|c|}{$\begin{array}{c}\text { GROUP II } \\
\text { Disc displacements }\end{array}$}} & \multirow{3}{*}{$\begin{array}{c}\text { GROUP III } \\
\text { Arthralgia } \\
\text { IIIa }\end{array}$} \\
\hline & & & & & & & \\
\hline & I (total) & Ia & $\mathrm{Ib}$ & II (total) & IIa & $\mathrm{IIb}$ & \\
\hline Women & $63(14 \%)^{* \$}$ & $52(11 \%)^{* \$}$ & $11(2 \%)$ & $132(29 \%)^{* \$}$ & $116(25 \%)$ & $16(4 \%)^{* \$}$ & $62(14 \%)^{* \$}$ \\
\hline Men & $19(4 \%)$ & $16(4 \%)$ & $3(<1 \%)$ & $70(15 \%)$ & $68(15 \%)$ & $2(<1 \%)$ & $19(4 \%)$ \\
\hline Total & $82(18 \%)$ & $68(15 \%)$ & $14(3 \%)$ & $202(44 \%)$ & $184(40 \%)$ & $18(4 \%)$ & $81(18 \%)$ \\
\hline
\end{tabular}

${ }^{*} \mathrm{P}<0.05$ comparison between women and $\mathrm{men} ;{ }^{\$} \mathrm{P}<0.05$ comparison between the percentage of women with the percentage of men in RDC/TMD groups; (\%) percentage off all respondents.

TABLE 5: Comparison of answers to selected questions of the questionnaire in the group of students exhibiting muscle disorders.

Selected question

\begin{tabular}{|c|c|c|c|}
\hline & I (total) & Ia & $\mathrm{Ib}$ \\
\hline \multicolumn{4}{|c|}{ Emotional burden } \\
\hline Yes & $58(13 \%)^{* \$}$ & $48(11 \%)^{\# \$}$ & $10(3 \%)$ \\
\hline No & $24(5 \%)$ & $20(4 \%)$ & $4(<1 \%)$ \\
\hline \multicolumn{4}{|c|}{ Fatigue and tightness of the facial muscles } \\
\hline Yes & $44(10 \%)^{* \$}$ & $38(8 \%)^{\# \$}$ & $6(1 \%)$ \\
\hline No & $38(8 \%)$ & $30(7 \%)$ & $8(2 \%)$ \\
\hline \multicolumn{4}{|c|}{ Cervical muscle pain } \\
\hline Yes & $55(12 \%)^{* \$}$ & $43(9 \%)^{\# \$}$ & $12(3 \%)^{\wedge \$}$ \\
\hline No & $27(6 \%)$ & $25(5 \%)$ & $2(<1 \%)$ \\
\hline \multicolumn{4}{|c|}{ Headache } \\
\hline Yes & $50(11 \%)^{* \$}$ & $39(9 \%)^{\# \$}$ & $11(2 \%)^{\wedge \$}$ \\
\hline No & $32(7 \%)$ & $29(6 \%)$ & $3(<1 \%)$ \\
\hline
\end{tabular}

GROUP I

Muscle disorders

\section{Selected RDC/TMD diagnoses}


by a greater number of estrogen and progesterone receptors in intra-articular cartilage in women with TMD. Thorn et al. refers that women report even slight pain during clinical examination, while men only when it is intensified, which could in a way contribute to achieving the above results [37]. This study has also indicated women as a group in which TMD is more frequent in all three diagnostic groups (I-III).

The most frequent disorder of TMJ in the examined population is disc displacement (44\%). Similar results were obtained by Karibe et al. [38] in patients aged between 16 and 18 (46.3\%), Miyake et al. [39] in patients with mean age 20 years (41.7\%) and Poveda-Roda et al. [40] in a group of people with mean age 40 years $(51.3 \%)$. The study of Manfredini et al. [41] in patients with mean age 32 years did not get a clear result stating a dominance of one of the disorders, while Guarda-Nardini et al. [42] in a group with average age of 41 reported a higher prevalence of pain in TMJ (61.4\%). Only Karibe et al. [38] assessed the frequency of type I disorders on the same level as type II in a group of subjects aged between 16 and 18. Stress, which is the main cause of the stomatognathic system disorders, is characteristic for young people up to 20 years old and for patients who are in their 40's, but the reasons of tension in each age group vary [38]. The comparison of data obtained in this and the above referred studies are presented in Table 3.

Not everyone is equally susceptible to the development of oral parafunction. For example, genetic factors affect the development of bruxism, since the significant influence of genetic polymorphism of receptor gene 5HT2 and particularly the presence of allele C rs6313 has been proved [43]. Further, the psychological factor and stress play also a significant role [44]. Each person perceives the world objectively and deals with stress differently depending on its psyche. Neurotic persons often relieve stress by straining the stomatognathic system through teeth clenching, contracting the masticatory muscles, and teeth grinding [14]. Consequently, an interdisciplinary approach from both dental clinicians and psychologists is prerequisite for a successful therapy in patients suffering from stomatognathic system disorders. Any therapeutic effort should exclude the cause, which in case of TMD and oral parafunctions is a failure to deal with stress effectively in everyday life.

\section{Conclusions}

(1) The prevalence of TMD in studied Polish student population is $54 \%$.

(2) TMD symptoms more often concern women.

(3) Emotional burden and excitability are factors that predispose to muscular disorders.

(4) The results based on RDC/TMD diagnoses are in accordance with current literature.

\section{Conflict of Interests}

The authors declare that there is no conflict of interests regarding the publication of this paper.

\section{References}

[1] S. F. Dworkin and L. LeResche, "Research diagnostic criteria for temporomandibular disorders: review, criteria, examinations and specifications, critique," Journal of Craniomandibular \& Sleep Practice, vol. 6, no. 4, pp. 301-355, 1992.

[2] A. Anastassaki Köhler, A. Hugoson, and T. Magnusson, "Prevalence of symptoms indicative of temporomandibular disorders in adults: cross-sectional epidemiological investigations covering two decades," Acta Odontologica Scandinavica, vol. 70, no. 3, pp. 213-223, 2012.

[3] F. Liu and A. Steinkeler, "Epidemiology, diagnosis, and treatment of temporomandibular disorders," Dental Clinics of North America, vol. 57, no. 3, pp. 465-479, 2013.

[4] C. di Paolo, G. D. Costanzo, F. Panti et al., "Epidemiological analysis on 2375 patients with TMJ disorders: basic statistical aspects," Annali di Stomatologia, vol. 4, no. 1, pp. 161-169, 2013.

[5] A. A. Köhler, A. Hugoson, and T. Magnusson, "Clinical signs indicative of temporomandibular disorders in adults: time trends and associated factors," Swedish Dental Journal, vol. 37, no. 1, pp. 1-11, 2013.

[6] U. Isong, S. A. Gansky, and O. Plesh, "Temporomandibular joint and muscle disorder-type pain in U.S. adults: the National Health Interview Survey," Journal of Orofacial Pain, vol. 22, no. 4, pp. 317-322, 2008.

[7] R. Benoliel and Y. Sharav, "Tender muscles and masticatory myofascial pain diagnosis: how many or how much?" Journal of Orofacial Pain, vol. 23, no. 4, pp. 300-301, 2009.

[8] American Society of Temporomandibular Joint Surgeons, "Guidelines for diagnosis and management of disorders involving the temporomandibular joint and related musculoskeletal structures," Journal of Cranio-Maxillofacial Surgery, vol. 21, no. 1, pp. 68-76, 2003.

[9] Y. Y. Shiau, H. W. Kwan, and C. Chang, "Prevalence of temporomandibular disorder syndrome (TMD) in university students-a third year report of the epidemiological study in Taiwan," Chinese Dental Journal, vol. 8, no. 3, pp. 106-116, 1989.

[10] T. I. Suvinen and P. C. Reade, "Temporomandibular disorders: a critical review of the nature of pain and its assessment," Journal of Orofacial Pain, vol. 9, no. 4, pp. 317-339, 1995.

[11] A. E. Sanders, G. D. Slade, and E. Bair, "General health status and incidence of first-onset temporomandibular disorder: the O PPERA prospective cohort study," The Journal of Pain, vol. 14, no. 12, pp. 51-62, 2013.

[12] M. Więckiewicz, A. Paradowska, B. Kawala, and W. Więckiewicz, "SAPHO syndrome as a possible cause of masticatory system anomalies-a review of the literature," Advances in Clinical and Experimental Medicine, vol. 20, no. 4, pp. 521-525, 2011.

[13] L. R. Bonjardim, M. B. Duarte Gavião, L. J. Pereira, and P. M. Castelo, "Anxiety and depression in adolescents and their relationship with signs and symptoms of temporomandibular disorders," International Journal of Prosthodontics, vol. 18, no. 4, pp. 347-352, 2005.

[14] L. B. Calixtre, B. L. da Silva Grüninger, T. C. Chaves, and A. B. de Oliveira, "Is there an association between anxiety/depression and temporomandibular disorders in college students?" Journal of Applied Oral Science, vol. 22, no. 1, pp. 15-21, 2014.

[15] S. S. Atsü and F. Ayhan-Ardic, "Temporomandibular disorders seen in rheumatology practices: a review," Rheumatology International, vol. 26, no. 9, pp. 781-787, 2006. 
[16] A. Paradowska-Stolarz and B. Kawala, "Occlusal disorders among patients with total clefts of lip, alveolar bone, and palate," BioMed Research International, vol. 2014, Article ID 583416, 6 pages, 2014.

[17] L. LeResche, L. Mancl, J. J. Sherman, B. Gandara, and S. F. Dworkin, "Changes in temporomandibular pain and other symptoms across the menstrual cycle," The Journal of Pain, vol. 106, no. 3, pp. 253-261, 2003.

[18] P. T. Koidis, A. Zarifi, E. Grigoriadou, and P. Garefis, "Effect of age and sex on craniomandibular disorders," The Journal of Prosthetic Dentistry, vol. 69, no. 1, pp. 93-101, 1993.

[19] H. M. Stallman, "Psychological distress in university students: a comparison with general population data," Australian Psychologist, vol. 45, no. 4, pp. 249-257, 2010.

[20] Y. S. Abou-Atme, M. Melis, K. H. Zawawi, and L. Cottogno, "Five-year follow-up of temporomandibular disorders and other musculoskeletal symptoms in dental students," Minerva stomatologica, vol. 56, no. 11-12, pp. 603-609, 2007.

[21] R. Grzywacz, "Overview of the stress in the student group on the basis of own research," Medycyna Rodzinna, vol. 62, no. 2, pp. 36-43, 2012.

[22] R. Ohrbach, Y. Gonzalez, T. List, A. Michelotti, and E. Schiffman, "Diagnostic Criteria for Temporomandibular Disorders (DC/TMD) Clinical Examination Protocol," 2014, http://www.rdc-tmdinternational.org/.

[23] RDC/TMD; Axis I: Clinical Physical Examination Forms and Specifications, Instructions for Scoring and Assessment; Axis II Biobehavioral Questionnaires, Instructions for Scoring and Assessment, University of Washington, Seattle, Wash, USA, 2011.

[24] M. Mankiewicz and H. Panek, "Influence of selected psychoemotional factors on the prevalence of temporo-mandibular dysfunctions," Prosthodontics, vol. 55, no. 5, pp. 344-349, 2005.

[25] M. K. Murphy, R. F. MacBarb, M. E. Wong, and K. A. Anthanasiou, "Temporomandibular disorders: a review of etiology, clinical management, and tissue engineering strategies," The International Journal of Oral and Maxilofacial Implants, vol. 28, no. 6, pp. 393-414, 2013.

[26] D. Manfredini, M. Marini, C. Pavan, L. Pavan, and L. GuardaNardini, "Psychosocial profiles of painful TMD patients," Journal of Oral Rehabilitation, vol. 36, no. 3, pp. 193-198, 2009.

[27] A. U. J. Yap, S. F. Dworkin, E. K. Chua, T. List, K. B. C. Tan, and H. H. Tan, "Prevalence of temporomandibular disorder subtypes, psychologic distress, and psychosocial dysfunction in Asian patients," Journal of Orofacial Pain, vol. 17, no. 1, pp. 21-28, 2003.

[28] D. Manfredini and F. Lobbezoo, "Role of psychosocial factors in the etiology of bruxism," Journal of Orofacial Pain, vol. 23, no. 2, pp. 153-166, 2009.

[29] A. S. Eswi, S. Radi, and H. Youssri, "Stress/ stressors as perceived by baccalaureate Saudi nursing students," Middle East Journal of Scientific Research, vol. 14, no. 2, pp. 193-202, 2013.

[30] B. T. Shaikh, A. Kahloon, M. Kazmi et al., "Students, stress and coping strategies: a case of Pakistani Medical School," Education for Health, vol. 17, no. 3, pp. 346-353, 2004.

[31] J. D. Rugh and W. K. Solberg, "Electromyographic studies of bruxist behavior before and during treatment," Journal of the California Dental Association, vol. 3, no. 9, pp. 56-59, 1975.

[32] G. B. Rollman and S. Lautenbacher, "Sex differences in musculoskeletal pain," The Clinical Journal of Pain, vol. 17, no. 1, pp. 20-24, 2001.
[33] R. L. Martins-Júnior, A. J. G. Palma, E. J. Marquardt, T. M. D. B. Gondin, and F. D. C. Kerber, "Temporomandibular disorders: a report of 124 patients," The Journal of Contemporary Dental Practice, vol. 11, no. 5, pp. 71-78, 2010.

[34] A. Tsang, M. Von Korff, S. Lee et al., "Common chronic pain conditions in developed and developing countries: gender and age differences and comorbidity with depression-anxiety disorders," Journal of Pain, vol. 9, no. 10, pp. 883-891, 2008.

[35] A. O. Abubaker, W. F. Raslan, and G. C. Sotereanos, "Estrogen and progesterone receptors in temporomandibular joint discs of symptomatic and asymptomatic persons: a preliminary study," Journal of Oral and Maxillofacial Surgery, vol. 51, no. 10, pp. 1096-1100, 1993.

[36] M. P. Warren and J. L. Fried, "Temporomandibular disorders and hormones in women," Cells Tissues Organs, vol. 169, no. 3, pp. 187-192, 2001.

[37] B. E. Thorn, K. L. Clements, L. C. Ward et al., "Personality factocs in the explanation of sex differences in pain catastrophizing and response to experimental pain," The Clinical Journal of Pain, vol. 20, no. 5, pp. 275-282, 2004.

[38] H. Karibe, G. Goddard, K. Aoyagi et al., "Comparison of subjective symptoms of temporomandibular disorders in young patients by age and gender," The Journal of Craniomandibular \& Sleep Practice, vol. 30, no. 2, pp. 114-120, 2012.

[39] R. Miyake, R. Ohkubo, J. Takehara, and M. Morita, "Oral parafunctions and association with symptoms of temporomandibular disorders in Japanese university students," Journal of Oral Rehabilitation, vol. 31, no. 6, pp. 518-523, 2004.

[40] R. Poveda-Roda, J. V. Bagán, Y. Jiménez-Soriano, and A. FonsFont, "Retrospective study of a series of 850 patients with temporomandibular dysfunction (TMD). Clinical and radiological findings," Medicina Oral, Patologia Oral y Cirugia Bucal, vol. 14, no. 12, pp. e628-e634, 2009.

[41] D. Manfredini, F. Piccotti, G. Ferronato, and L. Guarda-Nardini, "Age peaks of different RDC/TMD diagnoses in a patient population," Journal of Dentistry, vol. 38, no. 5, pp. 392-399, 2010.

[42] L. Guarda-Nardini, F. Piccotti, G. Mogno, L. Favero, and D. Manfredini, "Age-related differences in temporomandibular disorder diagnoses," Cranio-Journal of Craniomandibular Practice, vol. 30, no. 2, pp. 103-109, 2012.

[43] A. Yuka, S. Takeshi, I. Masakazu et al., "Association of genetic, psychological and behavioral factors with sleep bruxism in a Japanese population," Journal of Sleep Research, vol. 21, no. 3, pp. 289-296, 2012.

[44] V. Basić and K. Mrhulić, "The role of psycho-emotional tension and stress in the etiology of bruxism," Acta Stomatologica Croatica, vol. 37, no. 4, pp. 449-452, 2003. 


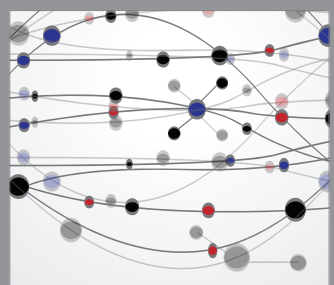

The Scientific World Journal
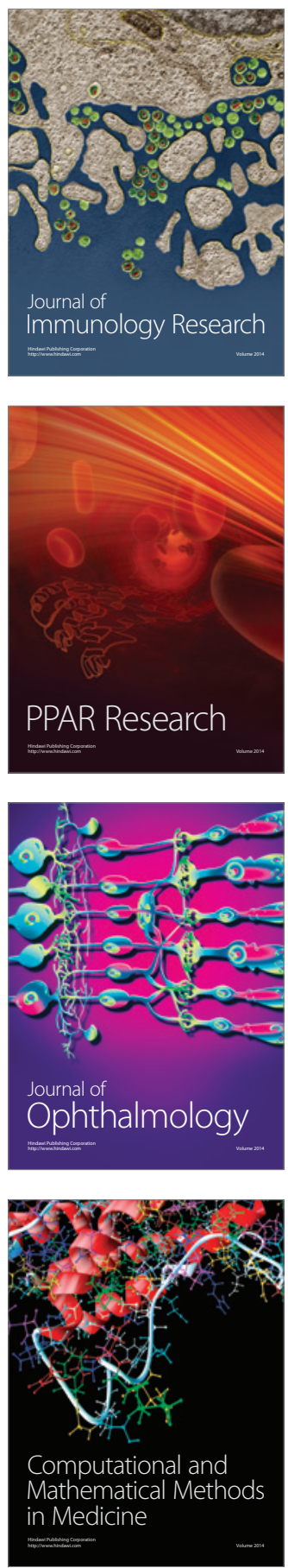

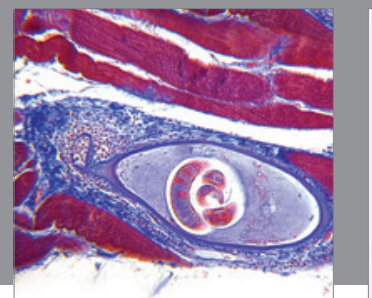

Gastroenterology

Research and Practice
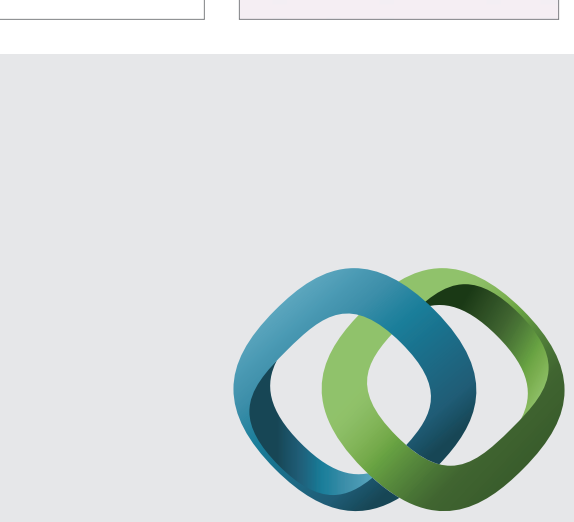

\section{Hindawi}

Submit your manuscripts at

http://www.hindawi.com
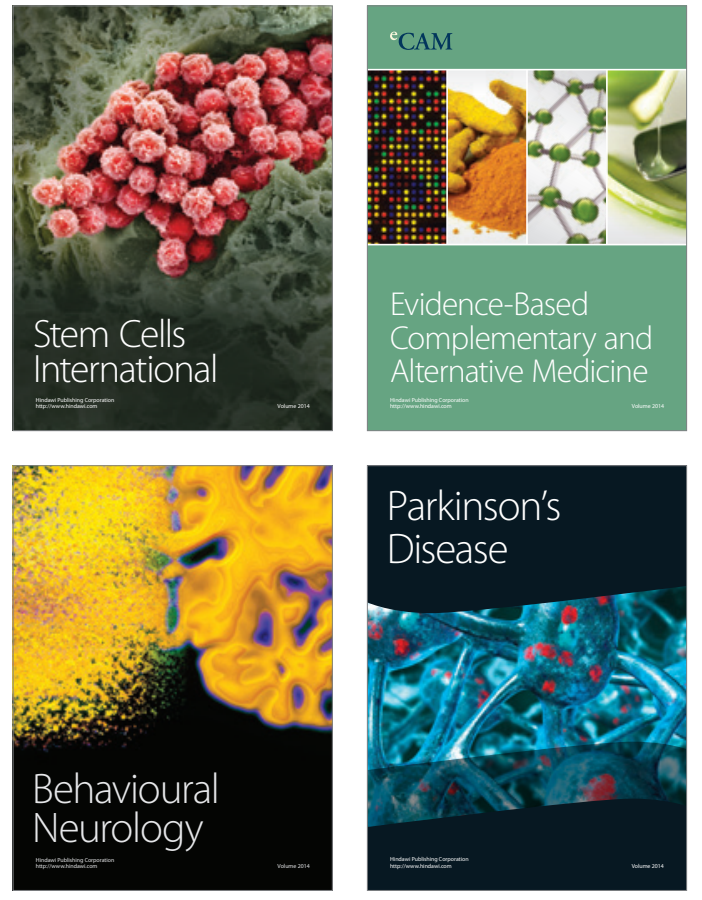
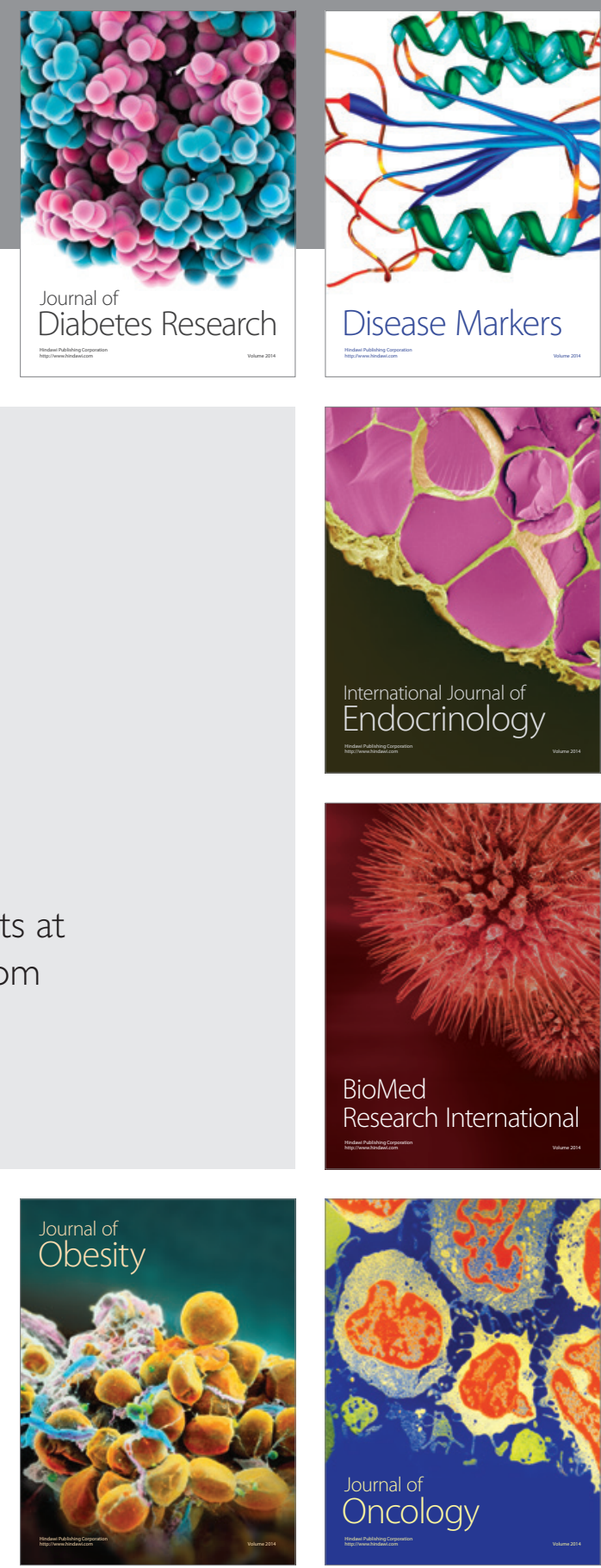

Disease Markers
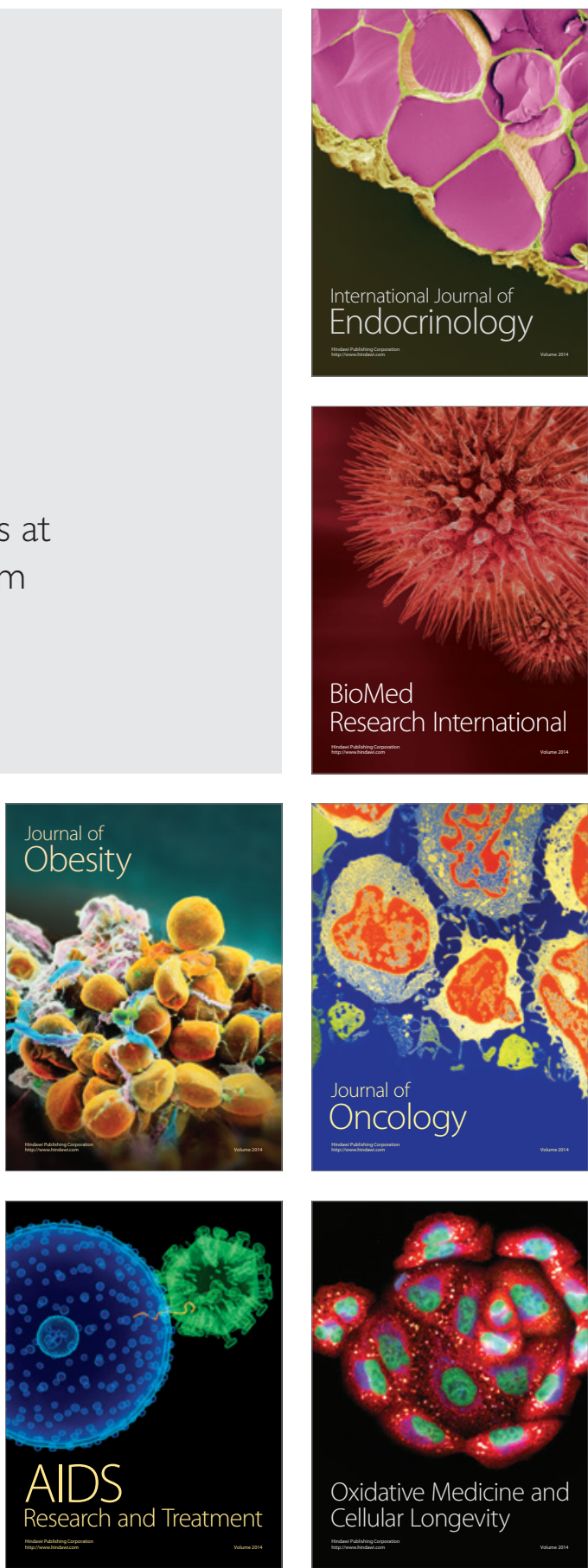